\title{
Working the Phones: Control and Resistance in Call Centres. Jamie Woodcock. Londres, Verso, 2017
}

\author{
Carlos Jesús Fernández Rodríguez \\ Universidad Autónoma de Madrid \\ carlos.fernandez@uam.es
}

Es bien sabido que en el Reino Unido existe, desde hace varias décadas, una rica tradición de estudios marxistas y postmarxistas sobre la realidad contemporánea del trabajo y las organizaciones que, bebiendo de distintas disciplinas de conocimiento (sociología, pero también estudios culturales o relaciones industriales) ha sido capaz de generar un corpus de investigaciones empíricas cualitativas de enorme interés. Adscribiéndose a distintas corrientes teóricas (Labour Process Theory, Critical Management Studies, Critical Labour Studies), diversos especialistas afiliados a universidades británicas han ido publicando detallados análisis etnográficos sobre las condiciones de trabajo existentes en las empresas del país, contribuyendo a generar importantes debates sobre fenómenos como el consentimiento, el género, la explotación, las emociones en el trabajo o el control. Uno de los textos más relevantes publicados recientemente en esta línea de trabajo ha sido precisamente la monografía que vamos a reseñar aquí, firmada por un joven investigador actualmente vinculado a la London School of Economics - aunque formado en el norte de Inglaterra-, Jamie Woodcock, y titulada Working the Phones, en el que se va a presentar una investigación sobre uno de los empleos más representativos de la nueva economía, el del teleoperador que llama, por motivos comerciales, desde un call center.

El tema que investiga Woodcock es un asunto relevante: se estima que, en el Reino Unido, el sector de los call centers emplea a aproximadamente un millón de personas, y ciertamente el lector de otras latitudes conoce de sobra la importancia de este sector en la economía y, al menos de forma superficial, las características de este tipo de empleo (aunque solo sea por haber recibido una llamada por parte de estas empresas). Woodcock considera a los call centers, de hecho, las fábricas de nuestro tiempo, especialmente interesantes porque, pese a su mala imagen social, proporcionan abundantes empleos que implican además una elevada carga de trabajo emocional, imprescindible para poder cerrar las ventas de forma exitosa. Además, en estos lugares se manifiestan, de alguna forma, las principales características del nuevo espíritu del capitalismo contemporáneo, siendo espacios emblemáticos del postfordismo: en ellos se encuentra las esencias de la globalización económica, la mediación tecnológica, la precariedad laboral asociada a la extensión de la subcontratación, el nuevo trabajo emocional, y las nuevas formas de control de los empleados, como prueba el espectacular volumen de rotación de la fuerza de trabajo ante la gran agresividad de las políticas de recursos humanos de estas compañías. Por todo ello, Woodcock argumenta en la introducción a la obra que este es un sector que merece la pena investigar en profundidad, con el fin de entender la lógica del trabajo asalariado en el neoliberalismo postfordista y comprender cómo perciben la explotación los explotados (siguiendo a Mario Tronti). Para ello, recurrirá a un enfoque etnográfico/narrativo muy particular, basado en sus propias experiencias como empleado en una compañía del sector, en el que explorará diferentes dimensiones del proceso de trabajo en este tipo de organizaciones y a las que se dedicará el resto de capítulos de la obra. 
Así, tras esta introducción, el segundo capítulo del libro se va a centrar en detallar la experiencia de la búsqueda de trabajo y firma del contrato, y en sus entretenidas páginas el lector tiene la oportunidad de apreciar la atmósfera de control que caracteriza el clima organizacional, con estrictos códigos de comportamiento. Es especialmente interesante la descripción que Woodcock hace de los espacios físicos del call center, particularmente el Break Room, habitación donde en ciertos momentos de la jornada se organizan reuniones de motivación para romper con la monotonía del trabajo. A partir de ahí, Woodcock describe en detalle la dinámica de trabajo cotidiana, donde tras trescientas o cuatrocientas llamadas diarias por parte de los teleoperadores, en muchas ocasiones no fructifica ninguna venta: las llamadas son además grabadas y supervisadas por los mandos intermedios, que se ocupan de proporcionar feedback a los empleados con un discurso moralista a medio camino entre el gerencialismo y el autoritarismo. El autor resume el proceso de trabajo en el call center como una suerte de taylorismo computerizado, sobrecargado de niveles de supervisión y en el que, finalmente, es la centralita la que marca los tiempos, tanto de los turnos como de los descansos; y paradójicamente, pese a este control automatizado, la eficacia "cuantitativa" del management termina fracasando en sus objetivos, pues en el fondo la actividad desempeñada tiene fundamentalmente características cualitativas (llamadas y conversaciones, al fin y al cabo, cargadas de elementos simbólicos, emocionales y narrativos) muy difíciles de gestionar. En este sentido, Woodcock proporciona estampas extraordinarias del trabajo cotidiano de estos empleados, como una llamada de una hora con una mujer que se lamenta de la pérdida de un hijo fallecido, otra a una persona gravemente enferma, y otras algo más agradables que nos permiten hacernos una idea de los desafíos y peculiaridades de este tipo de empleo, además de su dimensión emocional. También explica las dinámicas conflictivas en el espacio laboral, donde entran en conflicto, por un lado, el objetivo de los supervisores de "gamificar" el trabajo —en buena medida mediante la asignación de llamadas de acuerdo a las capacidades de venta percibidas del comercial, persiguiendo la instauración de tendencias competitivas dentro de la plantilla-, y por el otro, las estrategias colectivas de los empleados que, en ocasiones, ingenian en ocasiones métodos de interrupción del trabajo que terminan con un parón de las Ilamadas. Es llamativo que los teleoperadores, incluso consiguiendo dicho freno en las Ilamadas, son aun así incapaces de lograr su ansiada reducción de jornada y poder marcharse a casa antes de tiempo; a cambio, sufren otras exhibiciones de poder disciplinario, como son más reuniones de motivación hasta la hora de la salida 0 una intensificada vigilancia, que termina siendo contraproducente al generar una caída drástica de la motivación y el compromiso. ¡Cuánto nos dice de la calidad del empleo en estos centros y de su clima laboral! En general, la imagen que el lector se lleva de estos call centers es el de (por citar a Bifo) auténticas fábricas de infelicidad caracterizadas por someter a sus trabajadores a una profunda disonancia emocional entre un trabajo mental con un fuerte componente afectivo y muy agotador, y la mala calidad de dicho trabajo en términos de reconocimiento personal, condiciones y salario. Esta alienación genera un profundo rechazo al trabajo (en el sentido de evitarlo, escapando de él) que es respondida por el management, consciente de la situación, mediante algunas estrategias como incentivos salariales o reducción de horas (con modalidades de contrato a tiempo parcial), que no limitan de todos modos la brutal intensidad de la actividad durante la jornada laboral.

Tras esta vívida descripción de la jornada laboral y las actividades cotidianas, Woodcock dedica el tercer capítulo del libro a analizar el management del call center. Desde el principio, el papel de los supervisores es el de adoptar una posición autoritaria y muy poco flexible, poniéndose completamente del lado de la empresa e incrementando la vigilancia mediante la proliferación de reglas burocráticas y el recurso a la tecnología del grabado de llamadas como amenaza permanente. Su objetivo es vigilar los tiempos de las llamadas y, sobre todo, obtener unos bonus mensuales dependientes del rendimiento de sus equipos de trabajo. Debido a la política salarial, consistente en un porcentaje de sueldo fijo muy escaso, estos bonus son imprescindibles para poder obtener un salario dig- 
no, con lo que conforme avanza el mes la presión a la que los supervisores someten a la plantilla se va incrementando gradualmente (ya que necesitan asegurar sus bonus), aumentando al mismo tiempo su agresividad y capacidad de manipulación y generando un ambiente de trabajo muy desagradable. Además, en el call center se apuesta por una auténtica división sexista del trabajo en la que los supervisores, hombres, dan órdenes a una mayoría de trabajadoras recurriendo a estrategias como la gestión del cuadrante y sus turnos, despidos instantáneos, charlas manipulativas con un feedback muy vago, fomento de diversiones forzadas y humillantes, etc. A esta presión emocional se suman otros mecanismos de control que funcionan como un auténtico panóptico electrónico, en un esquema muy foucaultiano: todo se vigila mediante una mirada desde arriba (el puesto del supervisor se encuentra físicamente por encima del de los teleoperadores), y la escucha detallada de las entrevistas telefónicas. Además, se organizan reuniones inmediatamente después de los despidos para explicar los problemas generados por esas situaciones desagradables que han conducido a la extinción del contrato; se introducen técnicas de gamificación que sirven para incrementar la competencia entre empleados, etc. Woodcock nos ofrece un amplio catálogo de técnicas gerenciales de control basadas en métodos de castigo y recompensa, en las que el espacio de trabajo aparece, siguiendo la feliz expresión de Paul Edwards, como un "terreno en disputa", y donde tras un discurso gerencial oficial que reivindica la creatividad y la expresividad en el espacio de trabajo subyace un extraordinario aumento del control mediante los nuevos panópticos electrónicos.

En el cuarto capítulo la atención pasa a centrarse en la fuerza de trabajo y los momentos de resistencia al management que ocasionalmente emergen, partiendo de la base de que localizar esas acciones a través de la etnografía es siempre complicado, al existir muchas prácticas de difícil observación (por ejemplo la comprobación de una lentitud intencionada en el trabajo, o la identificación de sabotajes). No obstante, Woodcock argumenta que dichas dinámicas de control y resistencia están siempre presentes en estos es- pacios, y se inspira en las categorías definidas por la investigadora Kate Mulholland en su análisis de otro call center en Irlanda para certificar un amplio catálogo de resistencias: por ejemplo, vender los productos vía telefónica a amigos del teleoperador que los rechazan en un momento posterior, permitiendo computar la venta como realizada aunque al final no exista transacción económica; estrategias de pérdida de tiempo que incluyen alargamientos injustificados de los descansos, rondas de preguntas en las sesiones de motivación que las alargan, 0 incluso rupturas "accidentales" de los auriculares; conversaciones informales donde se critican de manera subrepticia aspectos de la organización del trabajo; y sobre todo, y como elemento más importante, la estrategia de "salida" (abandono de la compañía) en el sentido que utilizaría Albert Hirschmann y que, teniendo en cuenta las características del trabajo, parece según Woodcock la más lógica y racional, por cuanto sienta las bases de una verdadera liberación para el trabajador mediante el rechazo a un trabajo de mala calidad. Tras este catálogo de métodos de resistencia, el último capítulo del libro trata un tema de gran importancia como es el de la sindicación, frágil en un entorno con tanta rotación de personal y un control gerencial tan intenso y estricto. Woodcock describe en el capítulo las extraordinarias dificultades para la organización sindical en estos espacios, debido fundamentalmente al miedo generado por la elevada precariedad laboral. El autor reclama que se contextualice la actividad sindical en un espacio dominado por el neoliberalismo más duro, que va a ser muy difícil de desarrollar en un sector de un país en el que, en la actualidad, la conflictividad industrial y la afiliación sindical se han ido reduciendo paulatinamente desde la década de los setenta. Afirma además que va a ser el rechazo al trabajo (refusal to work), acción heredera del derecho a la pereza de Lafargue, la que tiene todo el sentido del mundo como estrategia básica de lucha en la actualidad. El libro finaliza con un apartado de conclusiones en el que no solamente el autor narra sus difíciles días finales en el puesto de trabajo, sino que realiza una valoración de enorme interés sobre las implicaciones metodológicas de las etnografías en las organizaciones, reivindicando la existencia de 
momentos de verdadera resistencia en este tipo de espacios organizacionales.

Working for Phones es una obra altamente recomendable para todos aquellos interesados en las ciencias sociales, que contarán con una obra de referencia tanto en términos de ejemplo de investigación de calidad, como de texto canónico para la docencia (pues es un libro conciso, vibrante, con indagaciones de enorme interés, que puede inspirar futuras vocaciones en el terreno de la sociología de trabajo). Situándose en un espacio intermedio entre el Labour Process Theory (al que Woodcock dice adscribirse) y los Critical Management Studies (con quienes, a juicio del que redacta esta reseña, el texto se identifica teóricamente mejor, especialmente cuando en varios pasajes del libro abundan las referencias tanto a Foucault como a los teóricos del General Intellect), el libro refleja de forma precisa y contundente la atmósfera de estos espacios organizacionales en los que se desempeñan actividades laborales con las que estamos muy familiarizados, y a los que raras veces prestamos atención. Los call centers son espacios representativos de la nueva economía del conocimiento, donde pese a los oropeles de Silicon Valley y otros centros de innovación empresarial, lo que se multiplica de verdad son los espacios desregulados y precarizados, a los que las nuevas tecnologías y los requerimientos de una conexión más emocional con el cliente han conducido no ya a un mayor enriquecimiento del trabajo (más liberador), sino más bien a la intensificación de la disciplina y el control. Esta magnífica etnografía expone esta realidad de la forma más cruda, proporcionando además numerosos detalles del trabajo cotidiano de los teleoperadores y supervisores, lo que nos proporciona una imagen, por momentos realmente trágica, de la realidad del trabajo postfordista. Es cierto que se trata, al fin y al cabo, de un estudio de caso, pero por otras referencias bibliográficas existentes (por ejemplo el artículo de Mulholland), parece bastante claro que lo descrito en estas páginas es el ambiente laboral y organización del trabajo común en este tipo de empresas. Quizá un elemento con el que el lector pueda discrepar, al menos ideológicamente, es la continua referencia al refusal to work (rechazo al trabajo) como estrategia preferente de resistencia (individual), frente a las posibilidades de una actividad sindical colectiva. En todo caso, más allá de estas y otras posibles disputas relacionadas con el marco teórico (en el que quizá se minusvaloren el papel de la regulación laboral y las características del contexto socioeconómico y la posición ideológica de cada uno, Working for Phones va a ser un texto fundamental en el campo de la sociología del trabajo y una aportación fundamental para una sociología crítica de las organizaciones, que además merecería, desde luego, una urgente traducción al castellano. 